\title{
Sistema de informação geográfica como ferramenta de apoio à outorga dos recursos hídricos subterrâneos no Distrito Federal
}

\author{
Tatiana Diniz, Gonçalves ${ }^{1}$, Henrique Llacer Roig ${ }^{1}$ \& José Eloi Guimarães Campos ${ }^{1}$
}

\begin{abstract}
Resumo O propósito deste trabalho foi desenvolver um método de integração de dados sobre o meio físico e o tipo de uso e cobertura vegetal da terra capaz de subsidiar de forma adequada os processos de gestão e outorga de direito de uso de água subterrânea no Distrito Federal. A integração dos mapas temáticos digitais permitiu estimar as condições de infiltração e recarga da área, a capacidade máxima de retenção de água dos solos, o índice de disponibilidade hídrica da região e o grau de favorabilidade à explotação de água subterrânea. Com base nos resultados e em observações de campo, foram propostos critérios de outorga norteadores da gestão de recursos hídricos subterrâneos do Distrito Federal.
\end{abstract}

Palavras-chave: Sistema de Informação Geográfica, água subterrânea, gestão e outorga.

\begin{abstract}
Geographic information system as a support tool to the management of groundwater resources of the Federal District, Brazil. The aim of this paper is to develop a method to the integration of physical environmental data and earth occupation and vegetation coverage maps appropriately to the management processes of groundwater and the proposition of water users rights in the Federal District, Brazil. By the integration of the digital thematic maps it was possible to obtain the infiltration and recharge conditions, the maximum capacity of water retention in the soils, the index of water exploitability and the groundwater exploitation favorability conditions. Based on the results and in field observations, there were proposed criteria to the management of groundwater resources of the Federal District.
\end{abstract}

Keywords: Geographic Information System, groundwater, management, water user rights.

INTRODUÇÃO A utilização de água subterrânea no Distrito Federal tem sido uma alternativa para diversos setores usuários, visto que, essa Unidade da Federação, tem uma demanda hídrica crescente contra uma situação física de escassez de reservas superficiais.

Os maiores problemas relacionados à exploração de águas subterrâneas no Distrito Federal estão associados, principalmente, à impermeabilização das áreas de recarga, ao desmatamento, a compactação da superfície, a construção inadequada dos sistemas de captação, a contaminação dos aqüíferos, ao subdimensionamento e a má conservação das redes adutoras e dos sistemas de reservação, a falta de controle dos volumes bombeados e por último, e não menos importante, a falta de conhecimento sobre os sistemas aqǘf́reros e seu potencial.

Soma-se aos fatos mencionados, a ausência de ações, por parte da ADASA - Agência Reguladora de Águas e Saneamento, órgão responsável pelo gerenciamento dos recursos hídricos no Distrito Federal, que assegure a gestão integrada dos recursos hídricos, principalmente, no que diz respeito à efetiva implantação do processo de outorga de direito de uso de recursos hídricos. Atualmente, verifica-se que o referido processo ainda se apresenta de forma dispersa e incipiente com relação aos recursos hídricos subterrâneos, mesmo considerando que este é um dos principais instrumentos da gestão capaz de assegurar o controle quantitativo, qualitativo e de acesso à água e o efetivo exercício dos direitos dos usuários.
Assim, disponibilizar um sistema de informações com dados necessários à construção de um modelo de gestão e outorga de água subterrânea que garanta o uso sustentável das águas do Distrito Federal é uma iniciativa de grande importância para a região.

CARACTERÍSTICAS DA ÁREA Localizada no Planalto Central brasileiro, a região em estudo compreende o polígono do Distrito Federal, em altitudes que variam de 750 a 1.344 metros. Abrange uma área de aproximadamente $5.800 \mathrm{Km}^{2}$, limitada pelos paralelos de $15^{0} 30^{\prime}$ 'S e $16^{0} 03$ 'S; a leste, pelo rio Preto e, a oeste, pelo rio Descoberto (Fig. 1).

O clima é caracterizado pela existência de forte sazonalidade: uma estação chuvosa e quente, entre outubro e abril, e outra fria e seca, de maio a setembro. A média pluviométrica anual varia entre 700 e 1.800 $\mathrm{mm}$ (Fig. 2), onde o mês de janeiro apresenta o maior índice pluviométrico médio ( $320 \mathrm{~mm} / \mathrm{mês})$ e os meses de junho, julho e agosto registram os menores (50 $\mathrm{mm} / \mathrm{mês})$. A temperatura média mensal varia entre $13 \mathrm{e}$ $22^{\circ} \mathrm{C}$, sendo setembro e outubro os meses mais quentes $\left(20\right.$ a $\left.22^{\circ} \mathrm{C}\right)$ e junho, o mais frio $\left(16\right.$ a $\left.18^{\circ} \mathrm{C}\right)$. A umidade relativa pode, durante alguns dias de agosto e setembro, atingir o valor mínimo de $11 \%$, enquanto que nos meses mais úmidos varia em torno de $75 \%$. A média de insolação no período mais seco, de abril a setembro, é de 200 h/mês e no período chuvoso, de outubro a março, é bem 


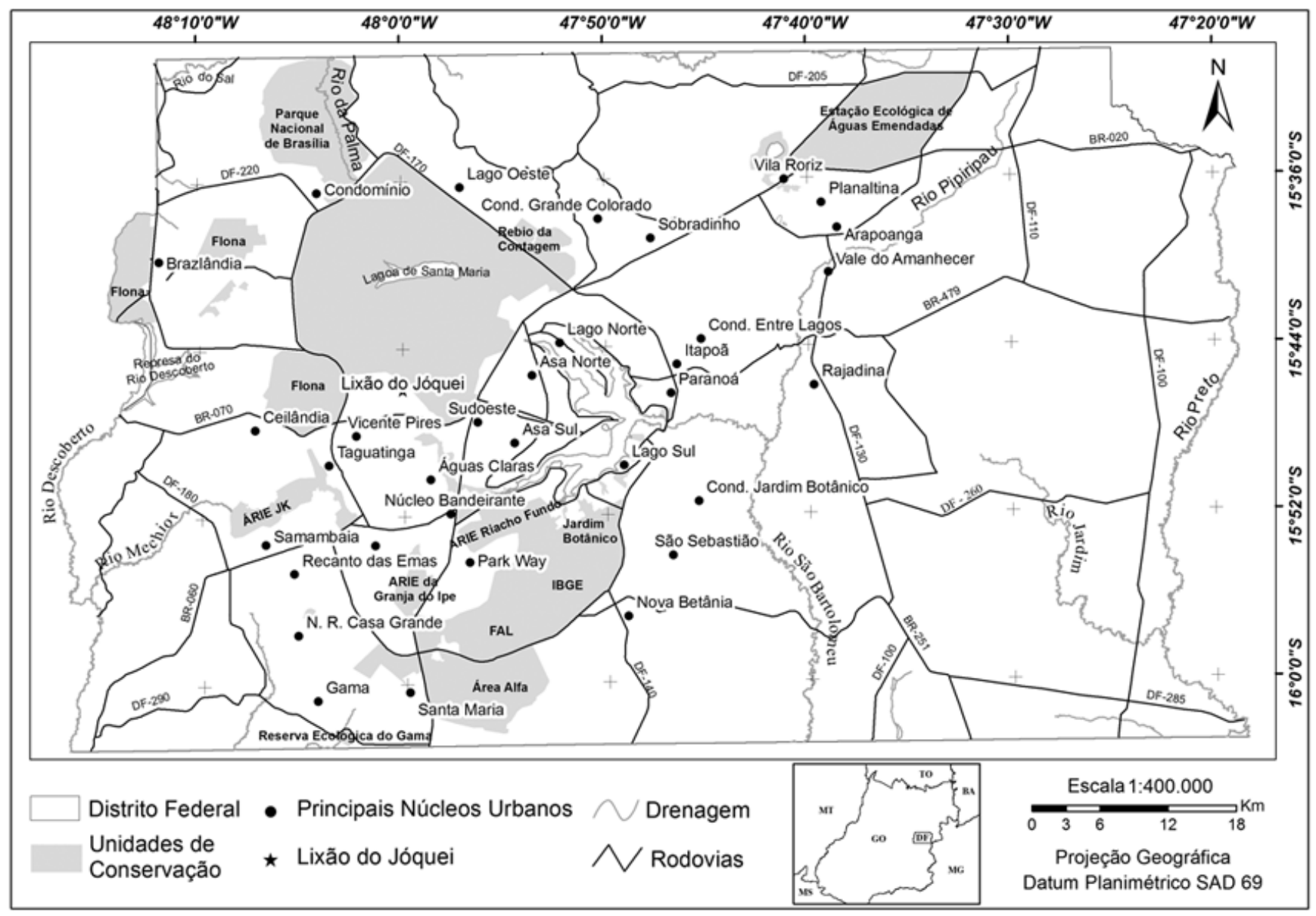

Figura 1 - Localização da área de pesquisa.

menor, com média de 130 h/mês (CODEPLAN 1984).

Conforme CODEPLAN (1976), a vegetação do Distrito Federal está situada na Província Fitogeográfica dos Cerrados. A paisagem descrita abrange dois grupos distintos: campos (limpo e sujo) e cerrados (campocerrado, cerrado e cerradão), com formações adicionais como matas ciliares, matas mesófilas e veredas.

Com base no mapeamento pedológico realizado pelo Serviço Nacional de Levantamentos de Solos (EMBRAPA 1978), as classes de solos, denominadas Latossolo Vermelho (LV), Latossolo Vermelho-Amarelo (LVA) e Cambissolo Distrófico (Cd), recobrem cerca de $90 \%$ da área do Distrito Federal (Fig. 3), e o processo pedogenético de laterização é o principal controlador da formação de solos na região.

O Distrito Federal está localizado no Planalto Central do Brasil e caracteriza-se pela ocorrência de extensos níveis planos e suave ondulados (região de chapadas), por níveis inclinados que se estendem da base das chapadas e morros residuais em direção aos vales (pediplanos) e por áreas entalhadas e dissecadas pelos rios Paranoá, São Bartolomeu, Preto, Maranhão e Descoberto (Novais Pinto 1994ab). As unidades geomorfológicas agrupam-se basicamente em três tipos de paisagens (macro-unidades): Região de Chapada, Área de Dissecação Intermediária e Região Dissecada de Vale. Ocorrem, também, em áreas mais restritas, as faixas de transição entre Região de Chapada e Região Dissecada de Vale, denominadas de Escarpas, e as faixas de limites entre Região de Chapada e Ârea de Dissecação Intermediária, denominadas de Rebordos (Martins \& Baptista 1998).

A coluna estratigráfica do $\mathrm{DF}$, considerando a ordem deposicional da base para o topo, é composta pelos grupos Canastra (15\% da área - filitos / corpos lenticulares de mármores e quartzitos), Paranoá (65\% da área - Quartzito / Metassiltitos / Ardósias / Metarritmito / Unidade Psamo-pelito-carbonatada), Araxá (5\% da área - xistos) e Bambuí (15\% da área - metassiltitos e arcóseos) (Fig. 4).

O contexto hidrogeológico possui dois domínios: o poroso e o fraturado. O domínio fraturado caracteriza-se pelo meio rochoso, em que os espaços ocupados pela água são representados pelos planos fraturados, microfraturas, diáclases, juntas, zonas de cisalhamentos e falhas. A classificação dos aqüíferos é baseada na classificação litoestratigráfica e contemplam as seguintes unidades: Sistema Aqüífero Paranoá (com os subsistemas $\mathbf{S} / \mathbf{A}, \mathbf{A}, \mathbf{R}_{3} / \mathbf{Q}_{3}, \mathbf{R}_{4}$ e $\mathbf{P P C}$ ); Sistema Aquífero Canastras (com os subsistemas $\mathbf{F}$ e F/Q/M) e os sistemas aquíferos Araxá e Bambuí. O domínio poroso no Distrito Federal é representado pelos solos aluviais e por aluviões (Campos \& Freitas-Silva 1998). 


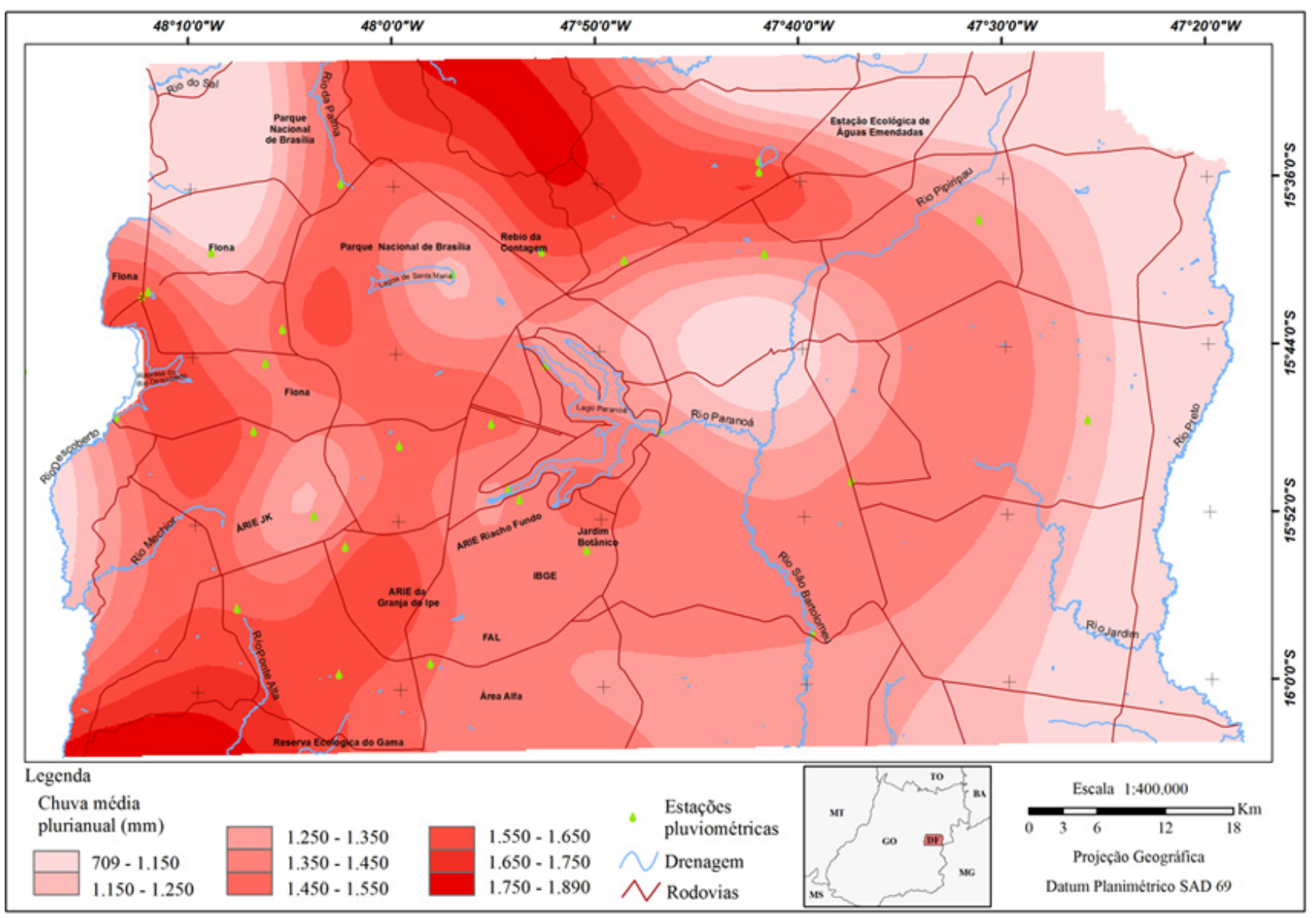

Figura 2 - Mapa de isoietas do Distrito Federal, construído com dados de 42 postos pluviométricos.

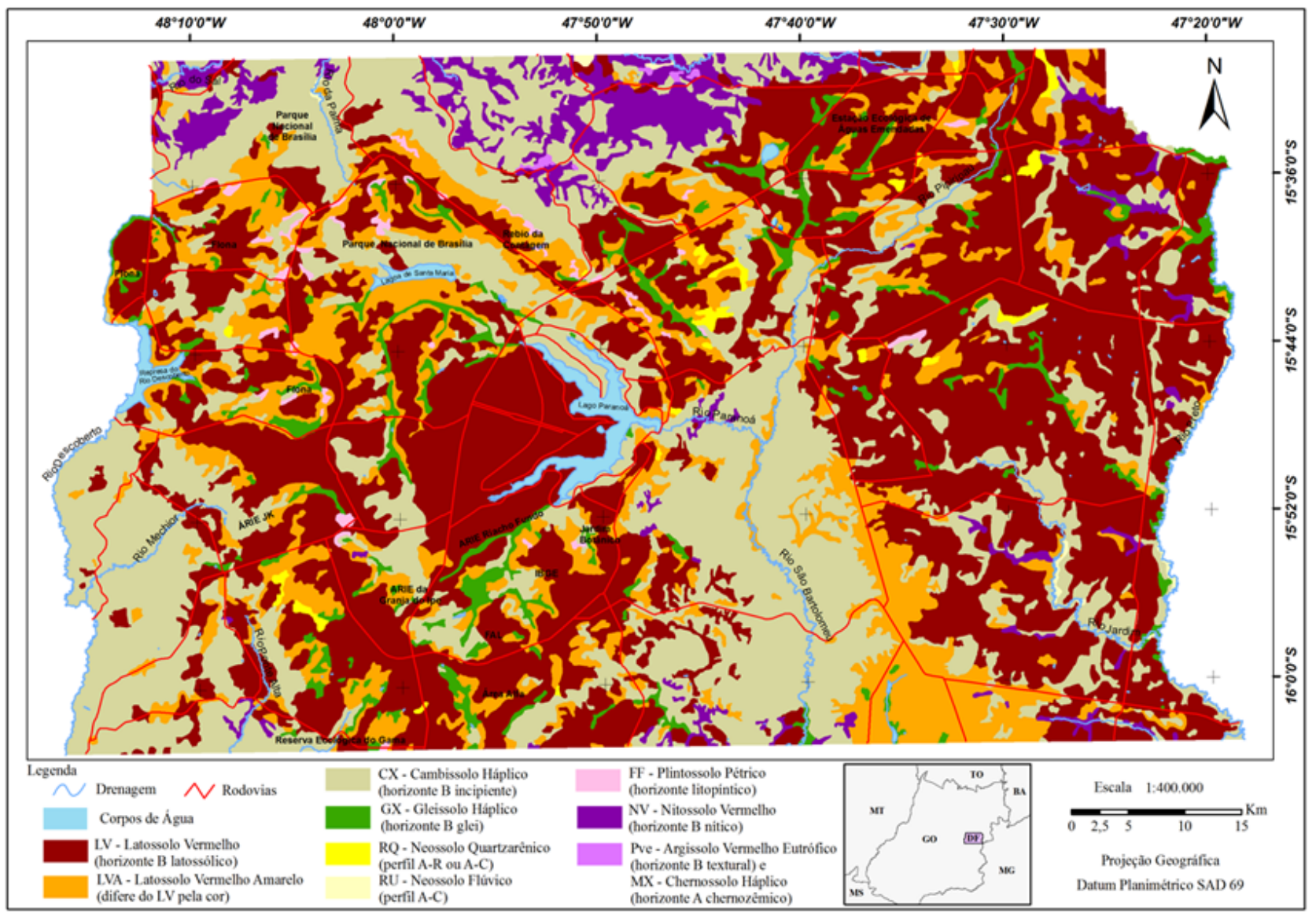

Figura 3 - Mapa de solos do Distrito Federal (modificado de EMBRAPA 1978). 


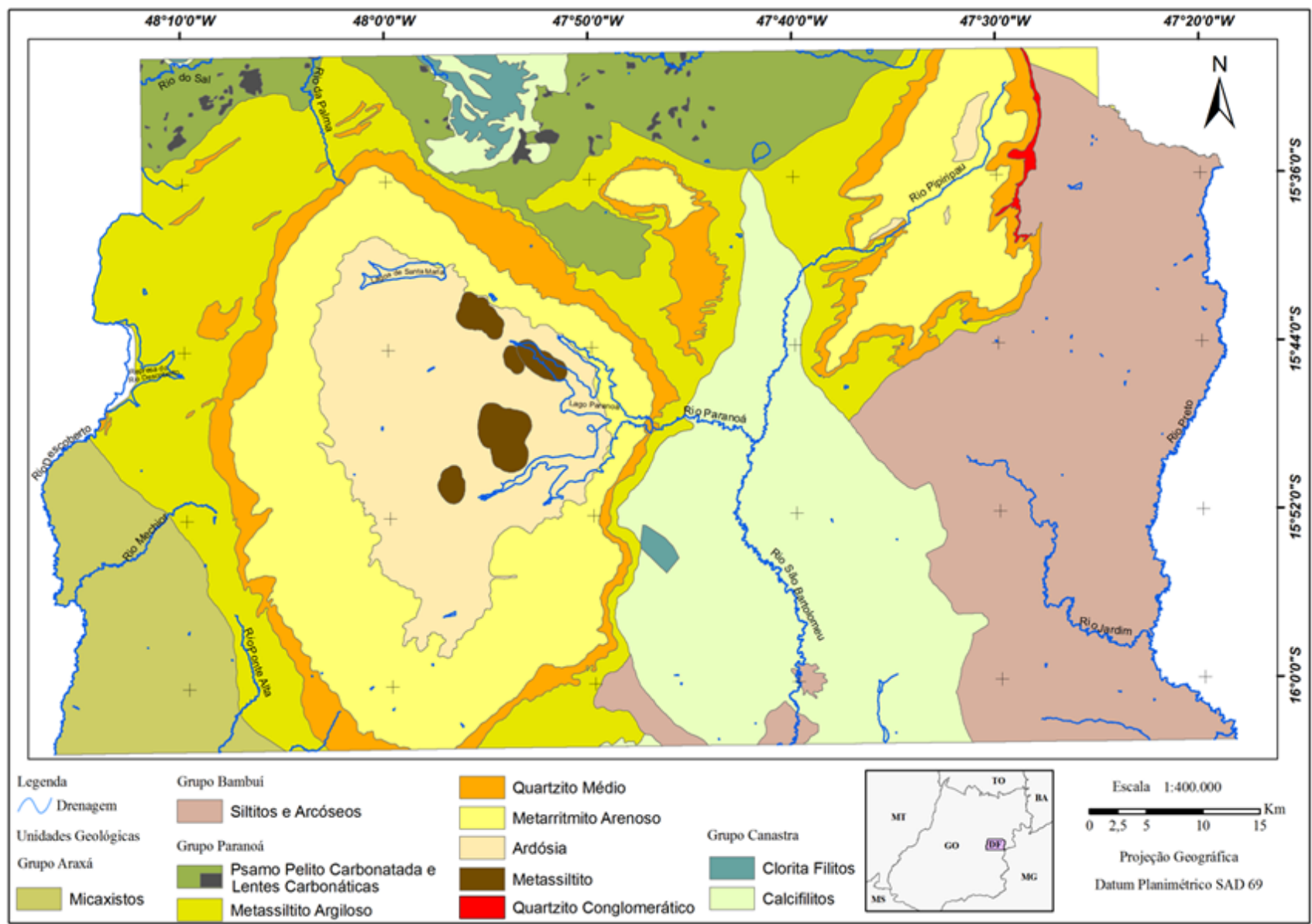

Figura 4 - Mapa litológico do Distrito Federal (modificado de Freitas-Silva \& Campos 1998).

MATERIAIS E MÉTODOS As informações utilizadas na estruturação da base de dados deste estudo são provenientes de várias fontes secundárias sob diferentes formatos e estruturas. Por este motivo, os dados armazenados foram convertidos ao formato shapefile (.shp) e reprojetados para o sistema de projeção UTM, zona 23 e datum Sad 69.

A escala de trabalho foi definida em função dos dados existentes. Todos os mapas utilizados possuem escala com nível de detalhe igual ou maior que 1:100.000.

Os planos de informações utilizados foram: (a) Modelo Digital de Elevação (MDE) do projeto Shutller Radar Topography Mission (SRTM) (NASA 2006); (b) Mapa de isoietas construído a partir da interpolação dos valores de chuva média plurianual, das séries históricas de 35 anos (1971 a 2006), provenientes de 42 postos pluviométricos do Distrito Federal e entorno, extraídas do sistema HIDROWEB (ANA 2006); (c) Mapa de uso da terra e cobertura vegetal, confeccionado por meio da interpretação e classificação da imagem de satélite SPOT 5 (Systeme Probatoire d' Odservation de la Terre) sensor HRV (High Resolution Visible) com resolução espacial de $5 \mathrm{~m}$. As cenas utilizadas foram 709/381, $710 / 381$ e 710/382, adquiridas em abril de 2003, préprocessadas e cedidas pela CODEPLAN (2005), com as correções geométricas e radiométricas; (d) Mapa litológico, atualizado de Freitas-Silva \& Campos (1998), com base em trabalhos de campo; (e) Mapa hidrogeológico do domínio fraturado de Campos \& FreitasSilva (1998). Este mapa foi construído com base nos seguintes parâmetros: vazão média $(\bar{Q})$ de cada unidade geológica, características hidrodinâmicas, densidade e interconectividade de fraturas e feições reológicas; (f) Mapa de solos, modificado de EMBRAPA (1978), com edição das áreas urbanas e adaptação das classes de solo às novas especificações propostas pelo Sistema Brasileiro de Classificação de Solos - SBCS da EMBRAPA (Santos et al. 2006).

A análise e a integração dos dados foram executadas com auxílio de Sistema de Informações Geográficas (ArcGIS) de acordo com os passos apresentados no fluxograma metodológico (Fig. 5). Os procedimentos para geração dos mapas derivados encontram-se descritos abaixo.

O mapa de uso da terra e cobertura vegetal foi confeccionado a partir da classificação automática da imagem Spot 5, através do método da distância mahalanobis, e posterior edição das classes de interesse. Tendo em vista os objetivos deste trabalho, este mapa não apresenta grande número de classes como os mapas de usos tradicionais. Desse modo, o mapa traz as seguintes classes: corpos de água; cobertura vegetal natural (formações florestais, savânicas, campestres) e reflorestamento; área urbana com alta densidade de ocupação (mais de $70 \%$ de área impermeável); área urbana com 


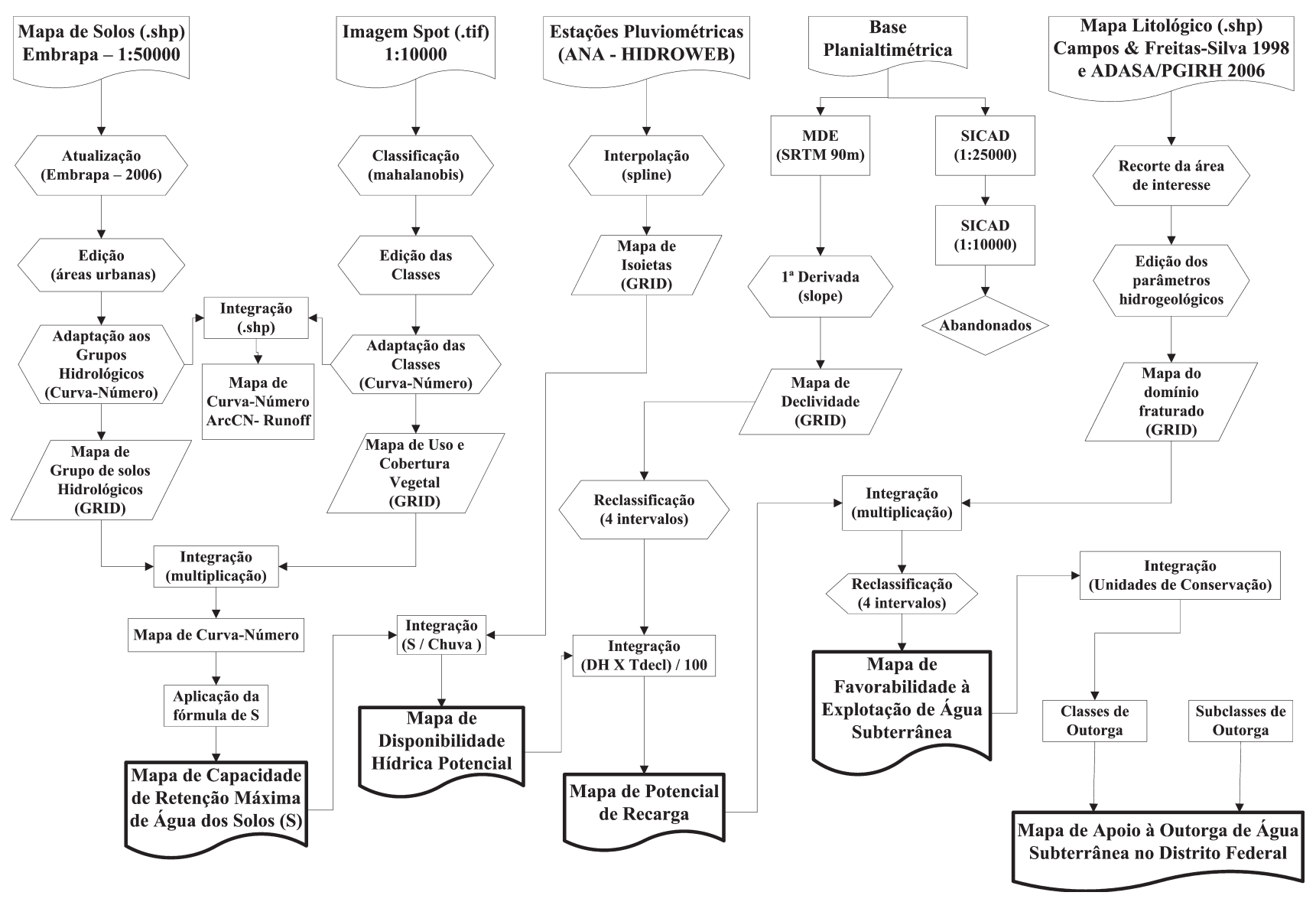

Figura 5 - Fluxograma Metodológico.

média densidade de ocupação (entre 40 e $70 \%$ de área impermeável); área urbana com baixa densidade de ocupação (menos de $40 \%$ de área impermeável); cobertura vegetal plantada (área agropastoril e área irrigada por pivô central) e outros usos (sistema viário pavimentado ou não, áreas de empréstimo, pedreiras, galpões, pista de pouso, solo exposto e áreas degradadas) (Fig. 6).

O percentual de áreas impermeáveis foi definido a partir da resposta espectral da imagem para cada classe, com posterior apoio de campo.

Para obter a capacidade de retenção máxima de água dos solos (S) foi utilizado o método do CurvaNúmero $(C N)$ (Ogrosky \& Mockus 1964). Este método, desenvolvido pelo Serviço de Conservação de Solos (SCS) do Departamento de Agricultura dos Estados Unidos (USDA), combina informações de uso e cobertura vegetal da terra com grupos hidrológicos de solos objetivando produzir o mapa de $C N$, que, por sua vez, resulta no mapa de "S", por meio da aplicação da seguinte equação (Ogrosky \& Mockus 1964) (1):

$$
S(\mathrm{~mm})=\frac{25400}{C N}-254
$$

Onde: 25400 e 254 representam volumes médios de escoamento superficial em função da precipitação.

A metodologia empregada para determinar o $C N$, seguiu a proposta de Lombardi-Neto et al. (1989) e Sartori (2004) onde os referidos autores redefiniram os grupos hidrológicos de solos de acordo com sua natureza física de 41 tipos de solos analisados na região sudeste brasileira. Considerando que os solos do Distrito Federal possuem características similares aos tipos de solos estudados por Lombardi-Neto et al. (1989) e Sartori (2004), optou-se por adaptar a mencionada proposta às condições da região em estudo, conforme mostra o mapa de grupos hidrológicos de solos do Distrito Federal (Fig. 7).

$\mathrm{O}$ índice de disponibilidade hídrica potencial foi obtido a partir da integração do mapa de capacidade de retenção máxima de água dos solos com o mapa de isoietas. Esse resultado representa uma estimativa do percentual das chuvas que potencialmente podem infiltrar em cada ponto num longo período de tempo, de forma a se considerar as médias das alturas pluviométricas como um dos fatores controladores dos processos de disponibilização de águas para aqüíferos.

Foi considerada apenas a altura pluvial média em intervalos de tempo não inferiores a cinco anos, por não se poder avaliar variações sazonais em curtos intervalos de tempo.

$\mathrm{Na}$ integração dos dados, as classes de $\mathbf{S}$ foram divididas pelo valor real contínuo no mapa de distribuição média de chuva. Obteve-se um índice que varia de 0 a $50 \%$, isto é, em condições ideais de chuva e de capacidade de saturação dos solos, a disponibilidade hídrica potencial pode ser, no máximo, de $52 \%$ da precipitação.

$\mathrm{O}$ potencial de recarga da área foi gerado a partir da integração do mapa de disponibilidade hídrica 


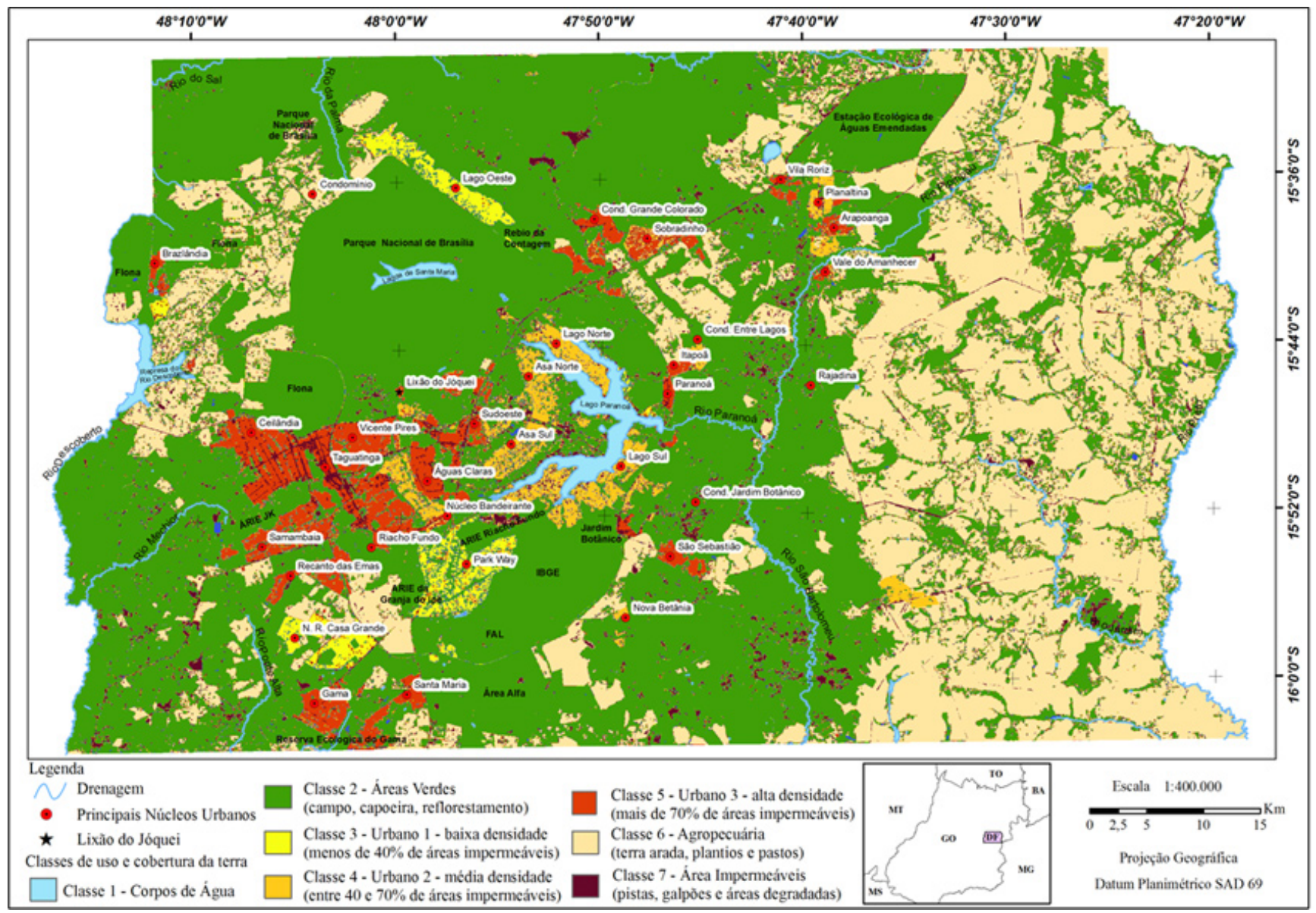

Figura 6 - Mapa de uso da terra e cobertura vegetal do Distrito Federal (confeccionado a partir de imagem SPOT 5 de 2005).

(DH) e da taxa de infiltração em função da declividade $\left(\mathrm{T}_{\text {decl }}\right)$, por meio da seguinte operação matemática (2):

$$
P R=\frac{\left(D H \times T_{d e c l}\right)}{100}
$$

o n d e , $\mathrm{PR}=$ potencial de recarga; $\mathrm{DH}=$ disponibilidade hídrica; $\mathrm{T}_{\text {decl }}=$ taxa de infiltração em função da declividade.

A taxa de infiltração em função da declividade foi definida subjetivamente, com base no funcionamento do fluxo superficial. As seguintes relações foram definidas: (a) declividade 0 a $8 \%$ - taxa de infiltração $95 \%$; (b) declividade 8 a $15 \%$ - taxa de infiltração $70 \%$; (c) declividade 15 a $30 \%$ - taxa de infiltração $45 \%$; (d) declividade $>30 \%$ - taxa de infiltração $5 \%$.

O potencial de recarga da área em estudo, associado à cada unidade hidroestratigráfica do meio fraturado, resultou, espacialmente, no potencial de disponibilidade hídrica subterrânea, o qual pode ser expresso pelo grau de favorabilidade à explotação de água subterrânea no Distrito Federal.

Os valores resultantes, embora tenham relações hierárquicas, são dados ordinais sem qualquer relação quantitativa. Sendo assim, o mapa de favorabilidade foi reclassificado por critério subjetivo, considerando as características do meio físico, o tipo de uso e cobertura vegetal, além das experiências e dos conhecimentos específicos da equipe de pesquisa.

O mapa de apoio à outorga foi construído a partir da análise do mapa de favorabilidade e das observações de campo. Assim, na versão digital do mapa (em Sistema de Informações Geográfica - SIG), a tabela de atributos contém as informações de todos os mapas utilizados para a geração deste produto de modo que, quando uma área for identificada em ambiente SIG, poder-se-á obter as seguintes informações: geologia, tipo de solo, percentual de declividade, altura de chuva em milímetros, tipo de uso, vazão média do aqüífero, grau de favorabilidade à explotação, bem como as classes e subclasses de outorga.

\section{RESULTADOS E DISCUSSÕES}

\section{Capacidade de Retenção Máxima de Água dos Solos}

(S) A combinação pareada dos atributos foi analisada individualmente e a tabela resultante foi reclassificada com os valores de $\mathbf{S}$. Estes valores representam a capacidade de saturação dos solos em milímetros por ano, conforme mostra a tabela 1.

O mapa de "S" (Fig. 8) mostra a distribuição da 


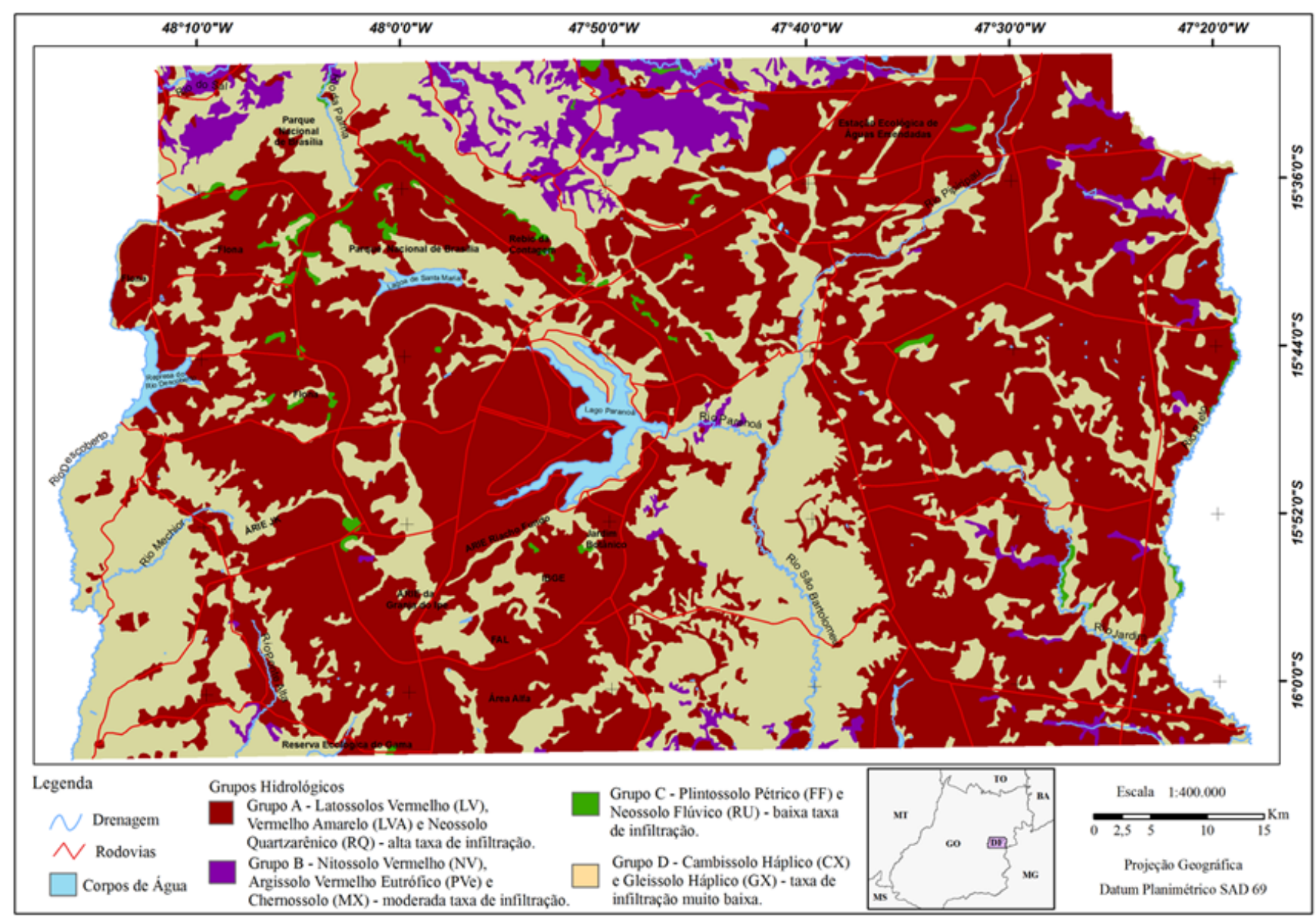

Figura 7 - Mapa de grupos hidrológicos de solos do Distrito Federal.

Tabela 1 - Capacidade de retenção máxima de água dos solos (mm/ano), adaptado de Lombardi-Neto et al. (1989) e Sartori (2004).

\begin{tabular}{|c|c|c|c|c|}
\hline \multirow{3}{*}{ Classes de Uso e Cobertura Vegetal } & \multicolumn{4}{|c|}{ Grupos Hidrológicos de Solos } \\
\hline & $\begin{array}{c}\text { A } \\
\text { (LV, LVA e RQ) } \\
\text { Solos muito profundos } \\
\text { com alta taxa de } \\
\text { infiltração. }\end{array}$ & $\begin{array}{c}\text { B } \\
\text { (NV, PVe MX) Solos } \\
\text { profundos com } \\
\text { moderada } \\
\text { taxa de } \\
\text { infiltração. } \\
\end{array}$ & $\begin{array}{c}\text { C } \\
\text { (FF e RU) } \\
\text { Solos pouco profundos } \\
\text { a } \\
\text { profundos com baixa } \\
\text { taxa de infiltração. }\end{array}$ & $\begin{array}{c}\text { D } \\
(\mathrm{GX} \text { e CX) } \\
\text { Solos rasos com } \\
\text { baixa taxa de } \\
\text { infiltração. }\end{array}$ \\
\hline & \multicolumn{4}{|c|}{ Capacidade de Retenção Máxima de Água dos Solos (mm/ano) } \\
\hline Classe 1 - Corpos de água. & 0 & 0 & 0 & 0 \\
\hline $\begin{array}{l}\text { Classe } 2 \text { - Campo, capoeira, reflorestamento - } \\
\text { combinação de gramas e pomares ou árvores, } \\
\text { fazendas e chácaras. }\end{array}$ & 381 & 162 & 89 & 63 \\
\hline $\begin{array}{l}\text { Classe } 3 \text { - Áreas urbanas com menos de } 40 \% \text { de } \\
\text { áreas impermeáveis. }\end{array}$ & 298 & 137 & 76 & 56 \\
\hline $\begin{array}{l}\text { Classe } 4 \text { - Áreas urbanas entre } 40 \text { e } 70 \% \text { de áreas } \\
\text { impermeáveis. }\end{array}$ & 119 & 67 & 41 & 31 \\
\hline $\begin{array}{l}\text { Classe } 5 \text { - Áreas urbanas com mais de } 70 \% \text { de } \\
\text { áreas impermeáveis. }\end{array}$ & 31 & 22 & 16 & 13 \\
\hline $\begin{array}{l}\text { Classe } 6 \text { - Terra arada, plantios em linha, } \\
\text { pequenos grãos ou cereais, semeação densa de } \\
\text { leguminosas ou dos pastos em rodízio, pastagem, } \\
\text { pastos ou campos de pastagem. }\end{array}$ & 149 & 89 & 59 & 45 \\
\hline Classe 7 - Áreas impermeáveis. & 5 & 5 & 5 & 5 \\
\hline
\end{tabular}

saturação potencial dos solos. Esta distribuição é decorrente da interação dos seguintes parâmetros: retirada da cobertura vegetal densidade de ocupação e forma desor- denada do padrão de uso da terra que proporcionam a impermeabilização das superfícies, diminuindo as áreas com maior potencial de infiltração. Em cidades como 


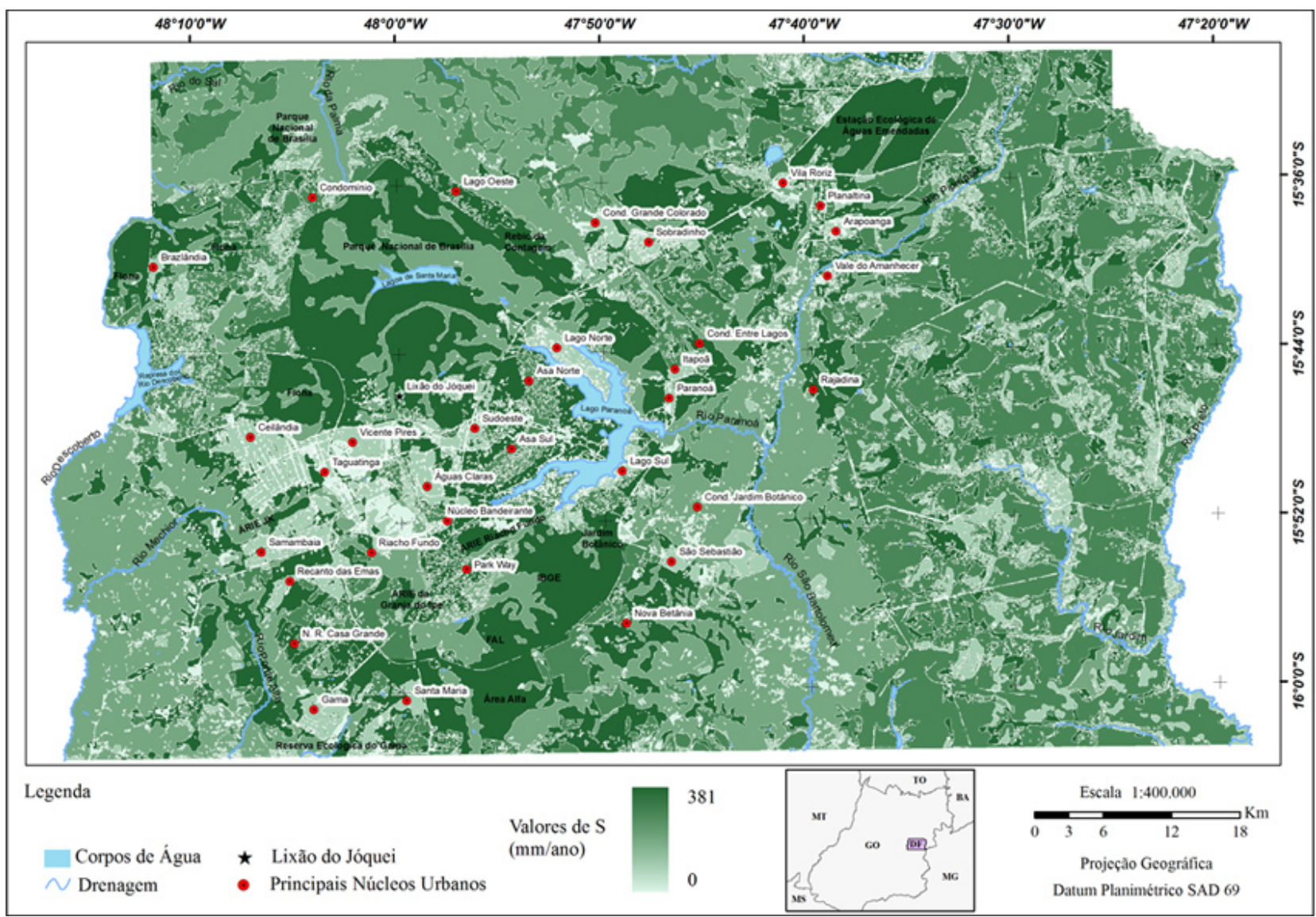

Figura 8 - Mapa de capacidade de retenção máxima de água dos solos (S).

Santa Maria, Gama, Recanto das Emas, Samambaia, Taguatinga e Ceilândia, mesmo estando inseridas no grupo de solos $\mathbf{A}$, apresentam taxas de infiltração baixas, correspondentes a cerca de $10 \%$ da altura pluvial.

No Plano Piloto, embora haja considerável densidade de ocupação, os valores de $\mathbf{S}$ são altos devido ao percentual de áreas verdes, fato este confirmado pelas observações de campo.

A influência dos solos pode ser confirmada a partir da analogia entre os resultados dos bairros Lago Sul e Lago Norte. Apesar de apresentarem baixos índices de impermeabilização, há considerável contraste pela predominância de solos das classes A (alta taxa de infiltração) nas áreas do Lago Sul e D (baixa taxa de infiltração) nas áreas do Lago Norte. Esse fato resulta em maiores valores de saturação potencial no Lago Sul em relação ao Lago Norte.

Com relação às áreas ocupadas por práticas agropecuárias, associadas aos solos do grupo $\mathbf{A}$, percebe-se resposta semelhante às áreas de vegetação nativa compostas por campos sujos e limpos. Cerca de $80 \%$ dessas áreas encontra-se com aproximadamente 40\% de capacidade de saturação do solo.

Disponibilidade Hídrica (DH) No mapa disponibilidade hídrica potencial da área (Fig. 9), constata-se que nos locais onde predominam baixos valores de saturação de água no solo (S), o percentual de disponibilidade hídrica também é menor, independentemente da distribuição das chuvas, como nas regiões de Taguatinga, Ceilândia e Riacho Fundo. Neste caso, vale mencionar a influência de áreas muito impermeabilizadas.

Baixos valores também são encontrados no vale do rio São Bartolomeu onde predominam solos rasos, pequenas taxas de impermeabilização e cobertura vegetal nativa ou pouco alterada.

Situação oposta é observada na unidade de conservação de Águas Emendadas. Embora não seja um local com elevados índices pluviométricos, registramse altos índices de disponibilidade hídrica, pois se trata de região de solos espessos e vegetação preservada.

Potencial de Recarga (PR) O potencial de recarga da área varia de 0 a $50 \%$ da precipitação (Fig. 10) e as melhores zonas encontram-se sobre solos profundos do grupo $\mathbf{A}$ e baixo grau de inclinação das superfícies, isto é, onde predominam declividades que variam de 0 a $8 \%$. As regiões mais altas também são favorecidas por apresentarem menor gradiente e, em geral, maior carga hidráulica, facilitando as condições de infiltração e a transferência de águas de precipitação para áreas mais profundas dos aqüíferos. Entretanto, ocorrem restrições à recarga decorrentes da impermeabilização das superfícies nas áreas de condomínios horizontais de alta densidade de ocupação (por exemplo, Condomínio Jardim Botânico e outros).

Nos perímetros urbanos com taxas de imper- 


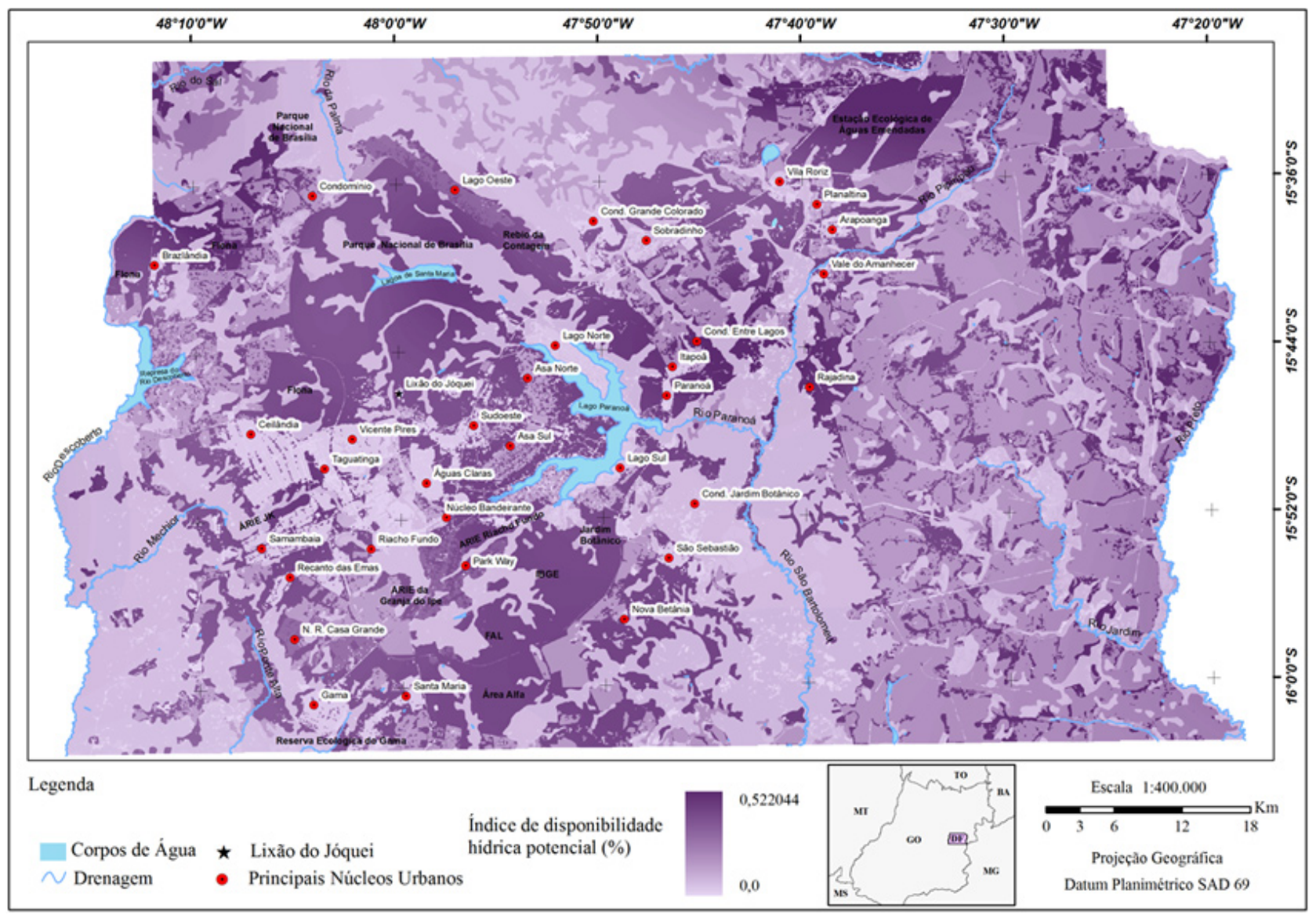

Figura 9 - Mapa de disponibilidade hídrica potencial do Distrito Federal (DH).

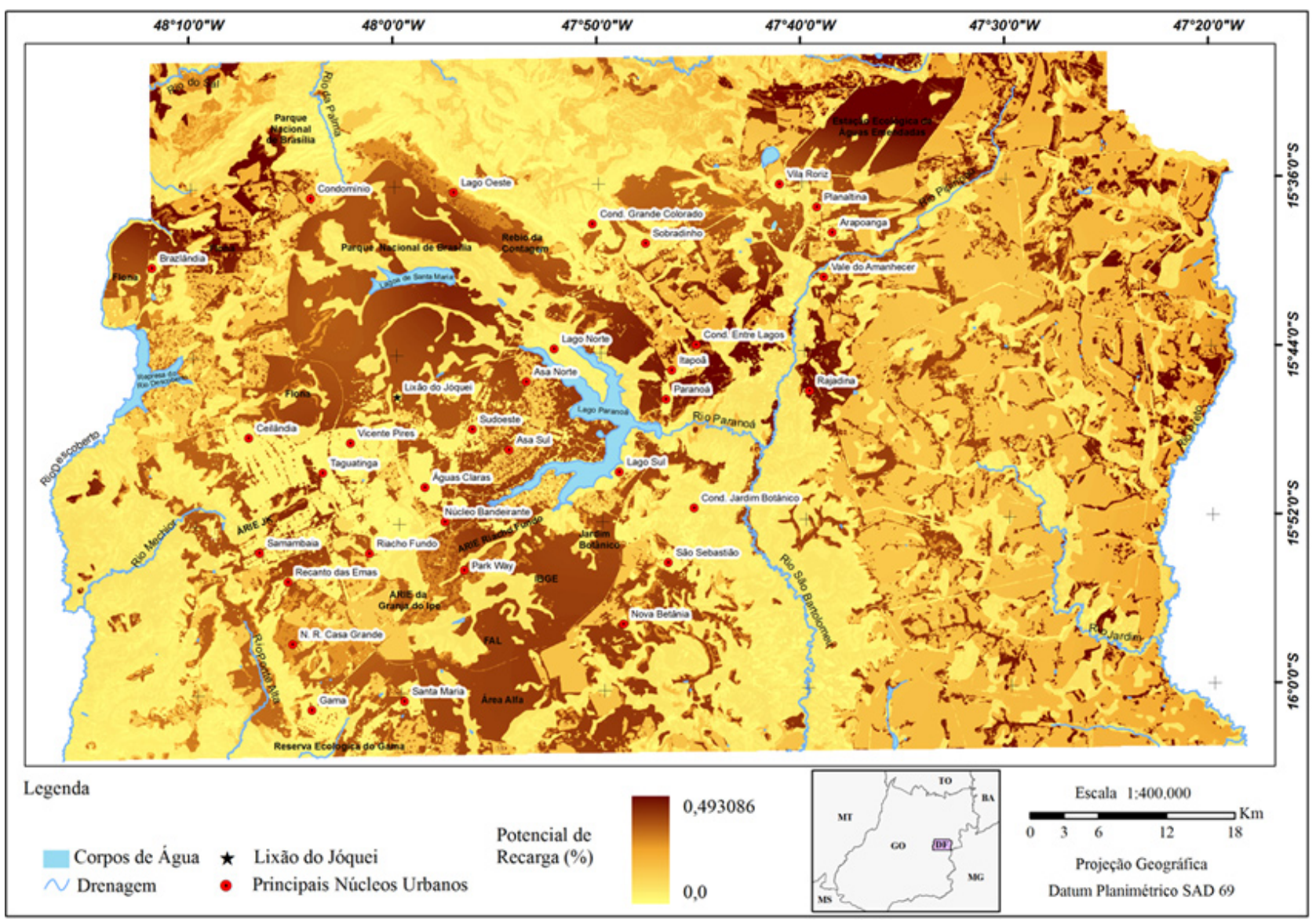

Figura 10 - Potencial de recarga do Distrito Federal. 
meabilização maiores que $70 \%$, o potencial de recarga varia de 1 a $4 \%$, como é o caso da Vila Roriz, condomínio de baixa renda, e das cidades de Sobradinho, São Sebastião, Paranoá, Santa Maria, Gama e outras.

É ainda relevante considerar a expressiva influência dos solos rasos, de textura grossa, como os cambissolos, comumente associados a regiões de vales dissecados, que, mesmo sob condições de vegetação preservada, resultam em áreas de baixo potencial de recarga. Esse exemplo mostra que considerar a declividade é fundamental nas análises da disponibilidade hídrica subterrânea de determinada bacia hidrogeológica.

Favorabilidade à Explotação Com base nas principais características do meio físico, foram definidas quatro classes de favorabilidade à explotação de água subterrânea conforme mostra a tabela 2 .

O mapa de favorabilidade (Fig. 11) mostra que as regiões mais favoráveis encontram-se em chapadas elevadas com vegetação preservada e sobre os sistemas aqüíferos mais produtivos do $\operatorname{DF}\left(\mathbf{Q}_{3} / \mathbf{R}_{3}\right)$. Este fato já era esperado, tendo em vista o baixo grau de impermeabilização e as características hidrodinâmicas do referido subsistema aqüífero.

As áreas densamente urbanizadas ou localizadas em regiões de vales dissecados apresentam índices menores, mesmo quando associadas aos aqüíferos de
Tabela 2 - Classes de favorabilidade à explotação de água subterrânea e suas principais características.

\begin{tabular}{|c|c|c|c|}
\hline $\begin{array}{l}\text { Favorabilidade } \\
\text { à Explotação }\end{array}$ & Principais Características & $\begin{array}{l}\text { Área } \\
\left(\mathrm{Km}^{2}\right) \\
\end{array}$ & Percentual \\
\hline $\begin{array}{l}\text { Muito } \\
\text { Favorável }\end{array}$ & $\begin{array}{l}\text { Solos espessos (K variando entre } \\
10-5 \text { e } 10-6 \mathrm{~m} / \mathrm{s}) \text {; declividade } \\
\text { baixa }(0-8 \%) \text {; vegetação } \\
\text { preservada, sem áreas urbanas } \\
\text { e vazão média elevada (> } \\
12.000 \mathrm{~L} / \mathrm{h})\end{array}$ & 623,5 & $11 \%$ \\
\hline Favorável & $\begin{array}{l}\text { Solos espessos (K variando entre } \\
10-5 \text { e } 10-6 \mathrm{~m} / \mathrm{s}) \text {; declividade baixa } \\
(0-8 \%) \text {; vegetação preservada, } \\
\text { áreas urbanas com menos } 40 \% \text { de } \\
\text { áreas impermeabilizadas e vazão } \\
\text { variando entre } 4.500 \text { e } 12.000 \mathrm{~L} / \mathrm{h} \text {. }\end{array}$ & $1.435,4$ & $25 \%$ \\
\hline $\begin{array}{l}\text { Pouco } \\
\text { Favorável }\end{array}$ & $\begin{array}{l}\text { Solos espessos ou rasos }(\mathrm{K} \\
\text { variando entre } 10-5 \text { e } 10-6 \mathrm{~m} / \mathrm{s}) \text {; } \\
\text { declividade variável }(3-15 \%) ; \\
\text { áreas urbanas variando entre } 40 \\
\text { e } 70 \% \text { de áreas impermeáveis } \\
\text { ou vegetação preservada e vazão } \\
\text { variando entre } 3.500 \text { e } 9.000 \mathrm{~L} / \mathrm{h} \text {. }\end{array}$ & $1.361,2$ & $25 \%$ \\
\hline $\begin{array}{l}\text { Não } \\
\text { Favorável }\end{array}$ & $\begin{array}{l}\text { Solos espessos ou rasos }(\mathrm{K} \\
\text { variando entre } 10-5 \text { e } 10-7 \\
\mathrm{~m} / \mathrm{s}) \text {; declividade variável }(0- \\
70 \%) \text {;áreas urbanas com mais de } \\
70 \% \text { de áreas impermeabilizadas } \\
\text { ou vegetação nativa em terrenos } \\
\text { com alta declividade e vazão } \\
\text { média entre } 3.500 \text { e } 6.500 \mathrm{~L} / \mathrm{h} \text {. }\end{array}$ & $2.318,5$ & $40 \%$ \\
\hline
\end{tabular}

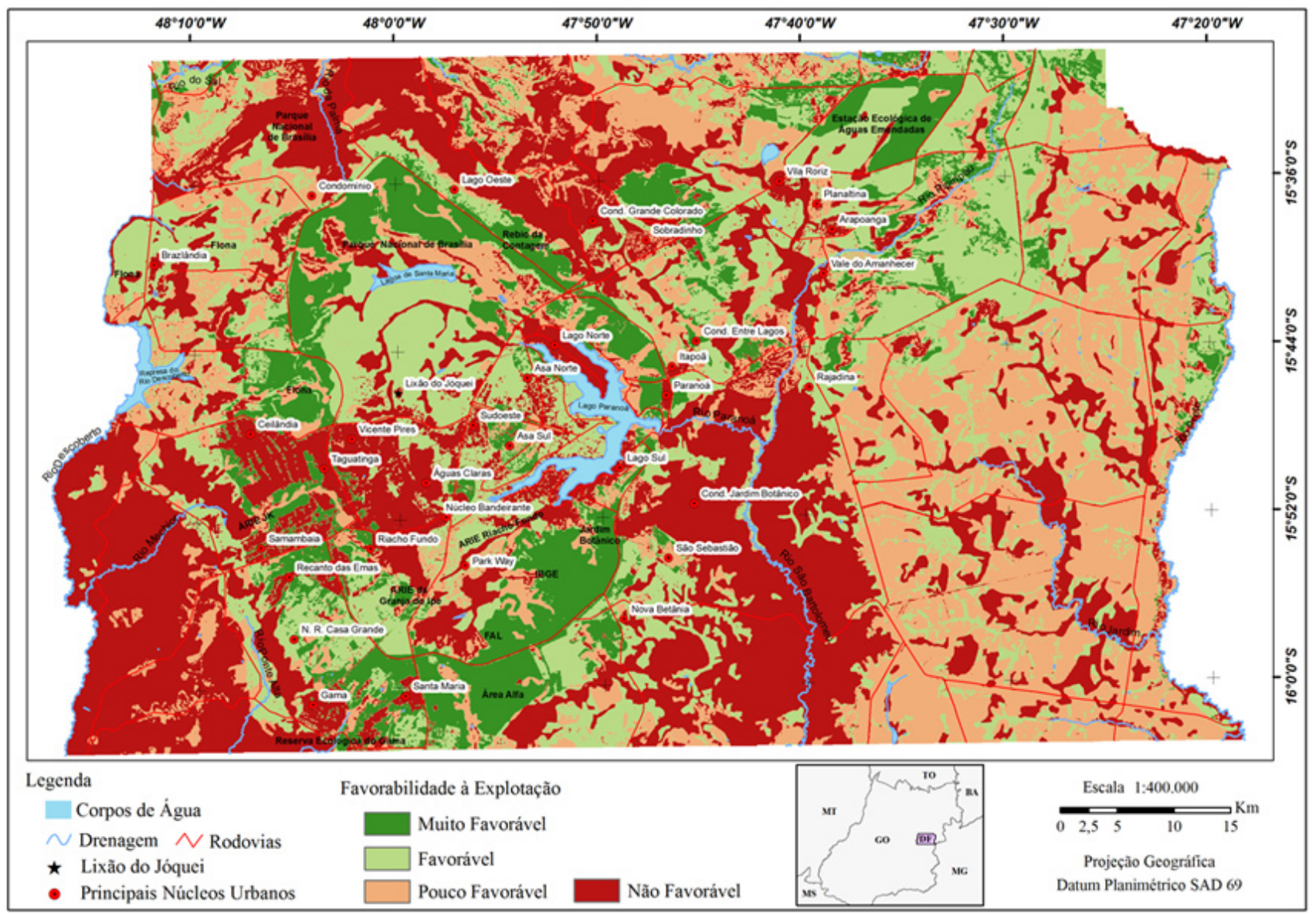

Figura 11 - Mapa de Favorabilidade à Explotação de Água Subterrânea do Distrito Federal. 
alta vazão no extremo norte do DF. Em cidades como Taguatinga, Ceilândia e Recanto das Emas, embora localizadas em regiões de baixa declividade, possuem baixo grau de favorabilidade em função do alto percentual de áreas impermeabilizadas.

Na porção leste do DF, onde predominam baixos índices de impermeabilização e declividade, o grau de favorabilidade é moderado devido às características intrínsecas dos sistemas aqüíferos da região.

Apoio à outorga de água subterrânea no Distrito Federal A fim de garantir a sustentabilidade dos aqǘferos, o presente estudo propõe que a outorga para explotação de água subterrânea seja classificada por um conjunto de códigos (números e letras) que qualifiquem a região por meio dos seguintes critérios:

(a) classes associadas às vazões e aos usos gerais devem ser denominadas por algarismos romanos maiúsculos, de I a IV, respectivamente relativas a $90 \%, 80 \%$, $60 \%$ e $50 \%$ da vazão de ensaio de bombeamento prolongado de 24 horas. O algarismo V representa uma classe de outorga especial destinada aos poços tubulares e aos poços para pesquisas científicas em áreas de unidade de conservação ambiental de grande restrição (ex. parques nacionais, reservas biológicas e estações ecológicas) ou a outras áreas de uso restrito (ex. áreas militares).

(b) subclasses associadas a restrições qualitativas (alto risco efetivo de contaminação) ou quanti- tativas (áreas sob pressão de explotação ou submetidas a sobrexplotação). Nesses casos deverão ser atribuídas as letras a, $\mathbf{b}$ ou $\mathbf{c}$, relacionadas ao progressivo aumento das restrições. Poços situados em áreas da subclasse a podem ser outorgados diretamente sem sequer a necessidade de visita a campo ou uso de critérios mais exigentes. Áreas cartografadas com índice b poderão ser outorgadas após visita de campo por parte do gestor responsável, que deverá avaliar a densidade de poços e os focos de contaminação. Áreas inseridas na subclasse c devem ter o pedido de outorga indeferida diretamente, pois já representam áreas com recursos hídricos subterrâneos comprometidos sob o aspecto da exaustão das disponibilidades ou da contaminação potencial.

As principais regiões do Distrito Federal, discriminadas pelas referidas classes e subclasses podem ser observadas no Mapa de Apoio à Outorga de Água Subterrânea do Distrito Federal (Fig. 12).

CONCLUSÕES E RECOMENDAÇÕES Com base nos resultados observa-se que a favorabilidade à explotação dos aqüíferos no DF decorre da integração dos seguintes fatores: tipo de solo, tipo de aqüífero fraturado local, declividade da superfície, tipo de uso e cobertura vegetal e variação da altura pluviométrica média.

Impermeabilização, explotação e contaminação podem ser consideradas o trinômio norteador da outor-

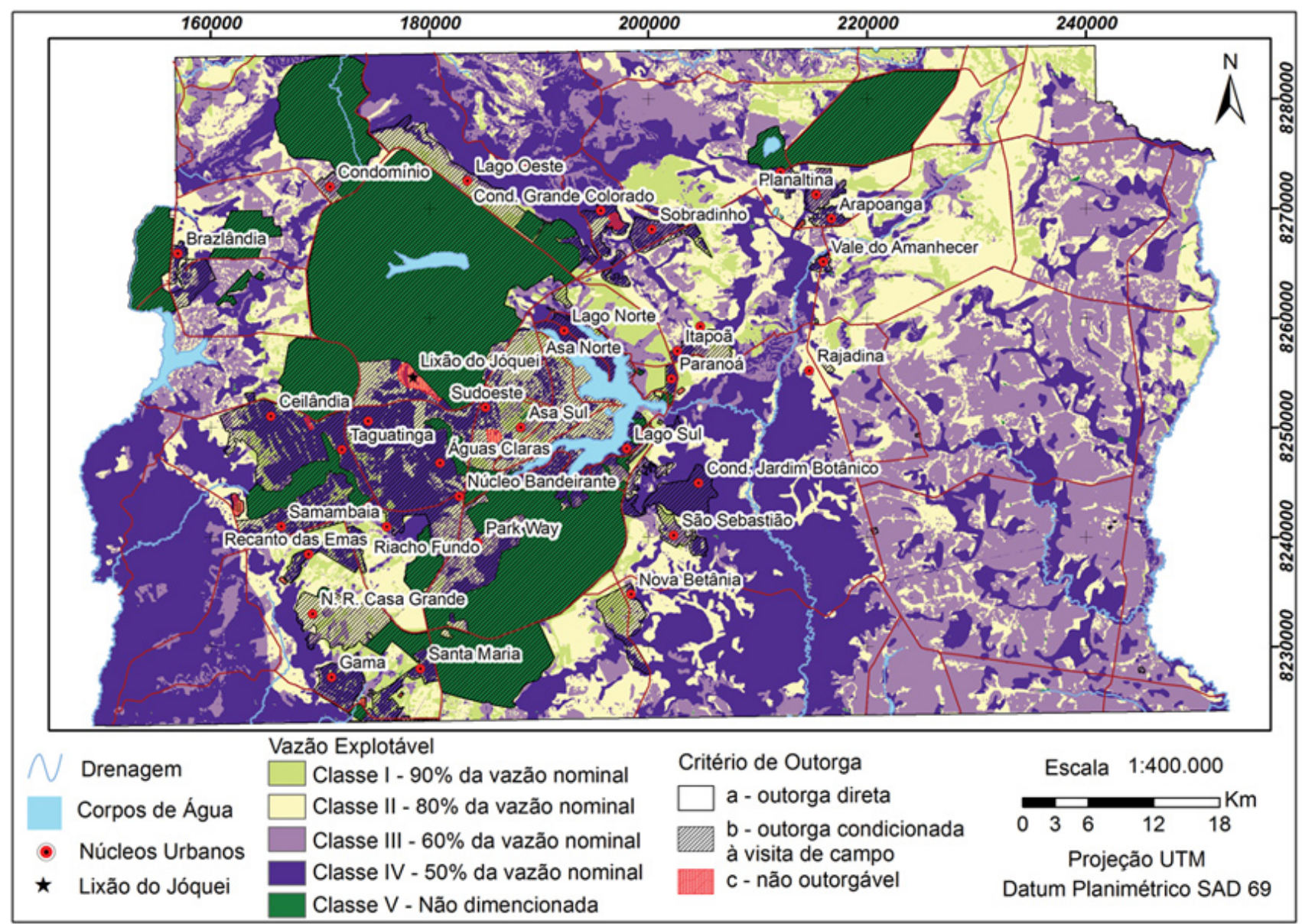

Figura 12 - Mapa de Apoio à Outorga de Água Subterrânea do Distrito Federal. 
ga de recursos hídricos subterrâneos, vez que, tais parâmetros são representativos das características de circulação, renovação e proteção das águas subterrâneas, os quais definem a sustentabilidade dos aqüíferos.

A impermeabilização, mesmo sendo superficial, afeta os processos de recarga, tendo em vista que a renovação dos aqüíferos tem início no processo de infiltração que ocorre na superfície. A explotação ou sobrexplotação pode exaurir os sistemas aqüíferos, tornando-os insustentáveis.

Os métodos de geoprocessamento empregados mostraram que este tipo de ferramenta permite adotar procedimentos de análise que atendem satisfatoriamente às necessidades desta pesquisa e que podem ser utilizados de forma adequada nas práticas de gestão do uso das águas subterrâneas.

O método Curva-Número $(C N)$, adaptado de Lombardi-Neto et al. (1989) e Sartori (2004), resultou em condições de saturação de água dos solos compatíveis com aquelas esperadas para o Distrito Federal. O emprego do referido método é recomendado quando se torna inviável o cálculo do balanço hídrico.

Por fim, recomenda-se que o banco de dados associado ao SIG, manipulado neste trabalho, seja realimentado periodicamente (a cada quatro anos), sobretudo no que diz respeito ao uso e à cobertura vegetal da terra, tendo em vista o caráter restritivo à recarga das áreas densamente impermeabilizadas. É, também, recomendado o desenvolvimento de balanços hídricos em pequenas bacias, preferencialmente em unidades de conservação ambiental, para validação dos modelos hidrogeológicos desenvolvidos para o DF e a otimização dos mapas de declividade de solos da região.

Agradecimentos Os autores expressam agradecimentos ao Instituto de Geociências da Universidade de Brasília e ao Conselho Nacional de Desenvolvimento Científico e Tecnológico - CNPq pelo apoio logístico de infra-estrutura e concessão de bolsa para realização desta pesquisa.

\section{Referências}

ADASA. 2006. Plano de Gerenciamento Integrado de recursos Hídricos do Distrito Federal - PGIRH. Agência Reguladora de Águas e Saneamento do Distrito Federal. Disponível em www.pgirh.df.gov.br. Acesso em 25 de agosto de 2006.

AGÊNCIA NACIONAL DE ÁGUAS (ANA). 2006. Sistema de Informações Hidrológicas - HIDROWEB. Disponível em: http://hidroweb.ana.gov.br. Acesso em 16/08/2006.

Campos J.E.G. \& Freitas-Silva F.H. 1998. Hidrogeologia do Distrito Federal. In: Freitas-Silva F.H. \& Campos J.E.G (eds.) Inventário Hidrogeológico e dos Recursos Hidricos Superficiais do Distrito Federal. Brasília. IEMA/ SEMATEC/UnB. Parte IV, p.1-85.

CODEPLAN. 1976. Diagnóstico do espaço natural do Distrito Federal. Brasília, GDF, 300p.

CODEPLAN. 1984. Atlas do Distrito Federal. Brasília, GDF, $78 \mathrm{p}$.

CODEPLAN. 2005. Cenas 709/381, 710/381 e 710/382 doBanco de Imagens de Satélite - SPOT 5 (Systeme Probatoire d' Odservation de la Terre) sensor HRV (High Resolution Visible). Brasília, GDF.

EMBRAPA. Serviço Nacional de Levantamento e Conservação dos Solos. 1978. Levantamento de Reconhecimento dos Solos do Distrito Federal. Escala 1:100.000. Rio de Janeiro, EMBRAPA, SNLCS, Boletim Técnico, 455p.

Freitas-Silva F.H. \& Campos J.E.G. 1998. Geologia do Distrito Federal. In: (eds.) Inventário hidrogeológico e dos recursos hídricos superficiais do Distrito Federal. Parte I. Brasília, IEMA-SEMATEC/UnB, p.1-86.

Lombardi-Neto F., Bellinazzi Júnior R., Galeti P.A., Bertolini D., Lepsch I.F., Oliveira J.B. 1989. Nova abordagem para o cálculo de espaçamento entre terraços. In: Fundação Cargill, Simpósio sobre terraceamento agrícola,
Campinas, atas, p. 99-124.

Martins E.S. \& Baptista G.M.M. 1998. Compartimentação geomorfológica e sistemas morfodinâmicos do Distrito Federal. In:___ (eds.) Inventário Hidrogeológico e dos Recursos Hidricos Superficiais do Distrito Federal. Brasília. IEMA/SEMATEC/UnB. Parte II, p.1-53.

NASA. 2006. Shutller Radar Topography Mission (SRTM) - Disponível em: http://www2.jpl.nasa.gov/srtm. Acesso em 21 novembro de 2005.

Novaes Pinto M. 1994a. Caracterização geomorfológica do Distrito Federal. In: Novaes Pinto M. (org.) Cerrado: caracterização, ocupação e perspectivas. $2^{\mathrm{a}}$ ed., Brasília, Editora UnB, p. 285-320.

Novaes Pinto M. 1994b. Paisagens do cerrado no Distrito Federal. In: Novaes Pinto M. (org.) Cerrado: caracterização, ocupação e perspectivas. Brasília. 2a ed., Editora UnB, p. 511-542.

Ogrosky H.O. \& Mockus V. 1964. Hydrology of agricultural lands. Sec. 21 in Handbook of hydrology by V.T. Chow. New York, McGraw Hill Book Co., p.1-79.

Santos H.G., Jacomine P.K.T., Anjos L.H.C., Oliveira V.A., Oliveira J.B., Coelho M.R., Lumbreras J.F., Cunha T.J.F. 2006. Sistema Brasileiro de Classificação de Solos SBCS. $2^{\mathrm{a}}$ ed., Rio de Janeiro: Embrapa solos, 306p.

Sartori A. 2004. Avaliação da classificação hidrológica do solo para determinação do excesso de chuva do método do serviço de conservação do solo dos Estados Unidos. Campinas, Dissertação de Mestrado, Universidade de Campinas, 159p.

Manuscrito ID 10338 Submetido em 20 de janeiro de 2008 Aceito em 15 de março de 2009 